\title{
El ‘empresario de sí mismo’: el olvido de Antonio Negri
}

\author{
The Entrepreneur of Himself: What Antonio Negri Missed
}

\author{
ANTONIO GÓMEZ VILLAR*
}

\begin{abstract}
Resumen: Antonio Negri es un gran conocedor de la obra del filósofo francés Michel Foucault. Su diálogo con él y con el post-estructuralismo francés es amplio y sostenido. Sin embargo, existe una importante omisión en la obra de Negri que este artículo pretende problematizar: la figura del 'empresario de sí mismo', tratada por Foucault en El Nacimiento de la biopolítica. Nuestra hipótesis es que la razón de dicha omisión la encontramos en la 'ontología del hacer' que atraviesa toda la obra de Negri. Atender a esta ausencia no es un fin en sí mismo. Nos interesa en tanto el 'empresario de sí' se nos presenta como una figura fundamental con la que entender los procesos de subjetivación propios del neoliberalismo; y en tanto encarna la temporalidad propia de la lógica de la explotación neoliberal.
\end{abstract}

Palabras claves: M. Foucault, A. Negri, empresario de sí mismo, fuerza de trabajo.

\begin{abstract}
Antonio Negri is an expert on the work of the French philosopher Michel Foucault. His dialogue with Foucault and French poststructuralism is broad and sustained. However, Negri made a significant omission regarding the 'entrepreneur of himself', a figure introduced in The Birth of Biopolitics. This article seeks to problematize what Antonio Negri missed. Our hypothesis is that the reason for the omission can be found in the 'ontology of doing' that traverses the work of Negri. Addressing this absence is not an end in itself. We are interested in both the 'entrepreneur of himself' as a fundamental figure through which we understand the processes of subjectivisation inherent to neoliberalism as well as the way in which the figure embodies the temporality of neoliberalism's logic of exploitation. This is not about the capturing of past antagonistic struggles, as Negri proposes, but rather the objectification of future time in the present in order to dispose of it in advance.

Keywords: M. Foucault, A. Negri, Entrepreneur of Himself, workforce.
\end{abstract}

\section{Introducción}

La argumentación del artículo está dividida en cinco partes: en primer lugar, contextualizaremos el encuentro que tuvo lugar en los años ' 70 entre los pensadores pertenecientes al operaismo italiano y al post-estructuralismo francés. Expondremos los principales lazos

Fecha de recepción: 31/07/2015. Fecha de aceptación: 23/01/2016.

* Universitat de Girona (UdG), profesor asociado. E-mail: antonio.gomez@udg.edu. Líneas de investigación: filosofía política, filosofía contemporánea, movimientos sociales, biopolítica. Dos publicaciones recientes: "El abandono: el lugar (des)habitado por las vidas precarias". Athenea Digital. Revista de pensamiento e investigación social. 1 - 16, pp. 113 - 136. 21/03/2016. ISSN 1578-8946; "Paolo Virno, lector de Marx: general Intellect, biopolítica y éxodo". Isegoría. Revista de Filosofía moral y política. 50, pp. 343 - 357. Consejo Superior de Investigaciones Científicas. Instituto de Filosofía, 2014. ISSN 1130-2097 
teóricos entre ambas corrientes de pensamiento, y prestaremos especial atención a la relación de Antonio Negri con Michel Foucault y Gilles Deleuze. En segundo lugar, atenderemos al concepto de 'lo común' en la obra de Negri, crucial para entender el porqué de la ausencia de la figura del 'empresario de sí mismo'. El modo en que Negri entiende la explotación postfordista, como expropiación de 'lo común', se nos revela fundamental. En tercer lugar, examinamos la relectura negriana de los conceptos de 'biopoder' y 'biopolítica' de Foucault, también decisiva, en la medida en que nos sitúa en esa ontología del hacer que recorre toda la obra del pensador italiano. A partir de la dimensión biopolítica de la 'composición técnica' del trabajo hoy; y de su concepción de 'lo común', siempre presentado como una relación positiva, habremos abonado el terreno para entender el porqué de la omisión antes referida. En cuarto lugar, expondremos nuestra crítica al planteamiento de Negri: el problema radica en la determinación ontológica en la que inscribe su concepción de 'lo común', en el hecho de que obvie que cada sujeto posee un capital, que el individuo se ha convertido en un espacio gestionable. Y, al tiempo, impugnaremos esa determinación ontológica a través de la concepción del neoliberalismo de Foucault, esta es, como modo de gubernamentalidad en el que las personas se rigen a sí mismas. Por último, sostendremos que desde la figura subjetiva del 'empresario de sí mismo', se rompe la lógica temporal en la que Negri inscribe su narrativa para comprender el campo social desde una perspectiva antagonista: la de un presente fundado en un pasado de luchas. Por el contrario, el 'empresario de sí' no expresa la captura de un tiempo pasado; sino la objetivación, en el presente, del tiempo futuro con el objetivo de disponer de él de antemano.

\section{El encuentro entre autonomismo italiano y el post-estructuralismo francés}

A partir de 1977, los pensadores de la operaismo italiano -Antonio Negri, Paolo Virno, Franco Berardi "Bifo" y Maurizio Lazzarato, entre otros- entran en contacto con el postestructuralismo francés a través de Foucault, Deleuze y Guattari. El exilio que emprendieron muchos de sus miembros a finales de los años setenta a París es sin duda un hecho biográfico fundamental que posibilita el contacto entre ambas corrientes. El momento clave fue septiembre de $1977^{1}$, en Bolonia:

Había tanques en la ciudad... algunos intelectuales franceses vinieron a Italia, estaban Deleuze, Foucault, toda la izquierda intelectual que se oponía a la represión [...] con la entrada de los tanques en pleno centro de Bolonia para rodear el barrio de la Universidad, y con varias muertes entre los manifestantes en Bolonia y en Roma. Un grupo de intelectuales franceses organiza un coloquio sobre la represión en Bolonia, en septiembre. Foucault, Deleuze y Guattari toman posición a favor del "laboratorio político" italiano y denuncian vehementemente la violencia del Estado (Negri, 2003, 27).

1 Tuvo lugar, en ese momento, una correspondencia entre la filosofía francesa y aquello que acontecía en Italia desde un punto de vista político. Es por ello que nos parece del todo oportuna la reflexión de Michael Hardt (Hardt, Virno, 1996), quien ha escrito que mientras la Francia del siglo XIX hizo política y Alemania hizo metafísica; en el siglo XX, Francia hizo metafísica e Italia política. 
A pesar de que las contingencias biográficas, marcadas por la fuerte represión sobre muchos de los miembros del operaismo italiano y la experiencia del exilio, están claramente a la base del encuentro entre ambas corrientes de pensamiento, consideramos que el encuentro no ha sido una mera casualidad motivada por estos acontecimientos políticos y biográficos. Antes bien, lo que abre la verdadera posibilidad de encuentro entre ambas corrientes son los lazos teóricos profundos que preexistían a la contingencia de dicho encuentro. En este sentido, el cruce entre el operaismo italiano y el post-estructuralismo francés es tanto un proyecto para reunir ambos pensamientos, como un proceso de revelamiento de resonancias previas. Desde esta perspectiva, podríamos hablar de una relación simbiótica entre la experiencia italiana y francesa, entre la French Theory y la Italian Theory ${ }^{2}$.

Los principales lazos teóricos entre ambas corrientes versan, sobre todo, en torno al rechazo de la consecuencialidad determinista entre la estructura del presente y la forma posible del futuro; la concepción del capital como relación social y no como cosa; la creencia en la autonomía singular como fuerza de enunciación, de creación y liberación; y el planteamiento del problema social como un problema de la autonomía y como posibilidad de una subjetivación autónoma.

En lo referente a la relación de ambas tradiciones con el pensamiento marxiano, hemos de apuntar que aunque las fuentes del pensamiento post-estructuralista y las del operaismo son radicalmente distintas -las fuentes francesas eran Baruch Spinoza, Henri Bergson, Sigmund Freud, etc.; y el operaismo comenzó con Karl Marx-, Deleuze y Guattari también articularon su pensamiento dentro de un dominio marxista. Más en concreto, desarrollaron sus conceptos en el contexto de una problemática marxista -de hecho, Deleuze nunca se enfrentó directamente con el marxismo, sino más bien con el estructuralismo-, a pesar de que ese dominio de pensamiento y esa problemática no era ni primordial ni consustancial a la formación intelectual de ambos.

En lo que a las transformaciones de ese origen marxiano del operaismo se refiere, el encuentro de la corriente operaista con la lectura marxiana en clave post-estructuralista tuvo como resultado la transformación de la corriente de pensamiento italiana en, lo que podríamos llamar, un 'pensamiento comunista de la diferencia'. En relación a ello, Negri sostiene que ni él ni Guattari abandonaron nunca el marxismo, porque no creían en una filosofía política que no estuviese centrada en el análisis del capitalismo como sistema inmanente que no cesa de repeler sus propios límites y que se los vuelve a encontrar en una escala ampliada, porque el límite siempre es el propio capital (Negri, 1993, 16).

Foucault, y con él Deleuze y Guattari, nos pusieron en guardia contra esta deriva. Eran revolucionarios. Cuando criticaban el estalinismo y las prácticas del "socialismo real" no lo hacían como hipócritas y fariseos, como "nuevos filósofos" del liberalismo, sino afirmando que sería posible expresar una nueva "potencia" del proletariado contra el "biopoder" capitalista. La resistencia al biopoder y la construcción

2 Italian Theory es el nombre acuñado por la academia angloparlante, al igual que sucedió antes con el término French Theory. Se considera el libro editado por Paolo Virno y Michael Hardt, Radical Thought in Italy, en 1996, como la irrupción oficial del operaismo italiano en el mundo académico norteamericano. 
de nuevos estilos de vida no aparecerían, pues, alejadas de la figura de la militancia comunista (Cocco, Negri, 2003, 260).

Otro aspecto importante que nos permite alumbrar el encuentro entre ambas corrientes es su oposición general al pensamiento hegeliano: "encontrar el pensamiento de Deleuze y Guattari, adquirir su modo de operar los conceptos y las palabras, ha significado para mí emprender una larga marcha de liberación de Hegel” (Bifo, 2013, 59). La oposición al pensamiento hegeliano está a la base del rechazo de ambas corrientes a un fundamento trascendental, planteando, por el contrario, un fundamento inmanente; así como un rechazo a un fundamento teleológico determinado, alumbrando, en cambio, un fundamento material y abierto. Frente a Hegel, desarrollan una concepción no dialéctica de la negación, el antagonismo.

En este sentido, la liquidación de toda concepción trascendental, la crítica de la causalidad determinista y la desmitificación de la teleología histórica que introduce el operaismo, abre un espacio de problematización que lo acerca al post-estructuralismo. En efecto, el problema consiste en cómo restaurar la subjetividad, cómo colocarla en un plano de inmanencia, sin fines externos a sí misma, y reinterpretar la dimensión biopolítica como terreno de los dispositivos constituidos, o sea, el campo de inmanencia como campo biopolítico.

\section{Antonio Negri y el post-estructuralismo francés}

Negri es uno de los autores que más se dejó afectar por el encuentro con los teóricos post-estructuralistas. Cuando se exilia a Francia, comienza a trabajar y ejercer como docente en el Collège International de Philosophie de la Universidad París VIII (Saint Denis), donde entra en contacto con Foucault, Deleuze y Guattari. Ya desde los años setenta Negri venía enfrentándose con el corpus teórico tradicional de los intelectuales del PCI:

Enjuagar la ropa íntima en el Sena, se trataba de confrontar el operaismo italiano y el pensamiento post-estructuralista francés, y de procurar así un cortocircuito entre Foucault y Deleuze por un lado, y las luchas obreras que se habían desarrollado en Italia -y no solo el pensamiento que habían producido-, por el otro. [...] Pero si esta situación representaba una hipótesis, el problema consistía en "encarnar" la filosofía francesa en la práctica italiana y, por consiguiente, sondear en la ontología teórica de la liberación en busca del contenido destructivo de la práctica (Negri, 2003, 18).

De entre los pensadores post-estructuralistas franceses, Toni Negri encuentra en Deleuze su interlocutor privilegiado: "no hay duda de que Deleuze y Guattari constituyen un referente decisivo en mi passe-partout de posmodernidad" (Casarino, Negri, 2011, 147). Por un lado, Negri intenta ir más allá de Marx; y, por otro, recoge la aportación deleuziana, traduciendo las implicaciones políticas de este planteamiento. El encuentro de Negri con Deleuze está mediado por Spinoza. La relación teórica de Negri con Deleuze comienza precisamente con la obra de este último sobre Spinoza, dado que el filósofo italiano no había leído ninguna de sus obras anteriores. En Negri, el paso de Hegel a Spinoza, la afirmación de la diferencia, supone el paso del sujeto antagónico al sujeto constituyente; del sujeto que se reapropia 
al sujeto que despliega su potencia. El esfuerzo de Negri se ha concentrado en conciliar el materialismo histórico, es decir, una determinada lectura no dialéctica de Marx con el pensamiento de la multiplicidad y la diferencia.

El encuentro de Negri con el post-estructuralismo francés es inconcebible sin la introspección filosófica que realiza, a finales de los setenta, en la cárcel, que da lugar a una "vuelta a Spinoza", y tuvo como resultado su obra La anomalía salvaje. Ensayo sobre poder y potencia en Baruch Spinoza. Su objetivo fue el de volver a hallar un asidero ontológico, materialista, una operación filosófica que marcará su obra posterior. Si su temprana formación jurídica había estado acompañada de una subjetividad trascendental y de una dialéctica -hegeliana y marxista-, a partir de finales de los setenta su pensamiento se orienta hacia un materialismo constituyente de las multitudes signado por la presencia de Maquiavelo, Spinoza y Marx. Negri seguirá a Althusser en la búsqueda de ese linaje materialista rastreando las huellas de los tres autores mencionados.

La originalidad de Negri radica, en buena medida, en haber sido capaz de enlazar la ontología sustancialista spinoziana con el materialismo histórico marxista. Con esta operación, Negri intenta rescatar a Marx de los límites impuestos por la filosofía idealista de la dialéctica. Y para ello, vincula a Marx con Spinoza al tiempo que esquiva a Hegel. La novedad filosófica sobre la que pone luz Negri es el hallazgo de una cierta homología entre el materialismo productivo, formulado por Spinoza en un nivel propiamente ontológico; y el mismo materialismo productivo, formulado por Marx no en un nivel ontológico, sino en el nivel de la historia.

Volviendo a la influencia de Deleuze en Negri, hemos de señalar que lo que más le sorprendió de Deleuze fue su capacidad para dar conceptualmente forma a ese conjunto de potencias. Dicho en otros términos: le sorprendió su capacidad para deshacer el horizonte estructural. En Imperio, Hardt y Negri reconocen explícitamente su deuda con la obra de Deleuze y Guattari Mil Mesetas. El trabajo de los filósofos franceses se le presenta a Negri y Hardt como desmitificador del estructuralismo y de todas las concepciones filosóficas, sociológicas y políticas que hacen de la fijación del marco epistemológico un punto de referencia ineludible:

Hasta aquel momento, aun dentro de la izquierda operaista, las definiciones de fuerza, de tendencia y de lucha se expresaban solo en función de una prefiguración general del sistema y dentro de ella. La estructura se hallaba siempre prefigurada. La acción de clase y, lo que era aún más importante para nosotros, las acciones de grupo y fuerzas sociales específicas emergentes, se entendían siempre dentro de una teleología necesaria y estructural [...] Pues bien, durante ese período pude decir que tuve que abandonar mi pensamiento, reescribirlo en francés. Mi encuentro con Deleuze me permitió superar esas limitaciones y supuso un cambio radical en mi investigación (Casarino, Negri, 2011, 153).

A partir de la lectura de Spinoza cobra fuerza en la obra de Negri su marcado carácter de rechazo al pensamiento de la trascendencia. El inmanentismo de la ontología materialista de Spinoza es la respuesta a la visión hegeliana de la historia como el despliegue de las fuerzas trascendentales. Su proyecto propone la elaboración de una genealogía materialista 
de las potencias constituyentes capaz de comprender las formas subjetivas que se producen en el antagonismo contra los poderes constituidos: "todo esto se inserta en la gran tradición materialista que va de Maquiavelo a Spinoza y a Marx y que solo nos dice una cosa: el deseo de liberación tiene una lógica ontológica irreductible. La inmanencia es este reino de posibilidades. Un telos no clásico sino ilustrado, no renacentista sino barroco, no moderno sino posmoderno" (Negri, 2006, 83).

En este sentido, Negri realiza una lectura del marxismo como pensamiento inscrito en una dialéctica no negativa, una dialéctica en la que no hay resolución -contrario al Aufhebung hegeliano-, no hay una superación de la contradicción. Es una lectura del marxismo como pensamiento sobre la ruptura de los términos que son puestos en relación; como pensamiento de la diferencia respecto de todo pensamiento de la identidad. Cuando la dialéctica es conceptualizada desde el antagonismo -entendido éste como lógica de la separación-, entonces la dialéctica es lucha entre contrarios, afirmación/negación. Si, por el contrario, la dialéctica fuese entendida en forma hegeliana, esto es, como síntesis, entonces ya no se presentaría como enfrentamiento, sino como negación de la negación, o sea, como superación de la relación antagonista. Para Negri, Spinoza funda el materialismo moderno, una filosofía inmanente, el ateísmo como negación de todo orden previo al obrar humano y a la constitución del 'ser'. Plantea el problema de la democracia sobre el terreno del materialismo, como crítica de toda mistificación jurídica del Estado. La democracia es política de la multitud organizada de la producción.

En lo que a la relación de Negri con Foucault se refiere, podemos afirmar que estuvo marcada por cierta ambivalencia. Por una parte, Negri defendió la metodología foucaultiana como esencial para la desmitificación de las instituciones jurídico-políticas de la modernidad y para el análisis de la fenomenología del poder; pero, por otra, llegó a la conclusión de que en Foucault, al final de su arqueología, no pudo aparecer un efectivo proceso de poder (Negri, 1982). Desde la perspectiva negriana, la principal limitación del proyecto foucaultiano radica en que el proyecto arqueológico siempre fue movido desde arriba hacia abajo, mientras que la preocupación de Negri es pensar la oposición desde el movimiento de abajo. Escribe Negri: "escuché sus conferencias un par de veces en el Collège de France, y sus argumentos eran casi los de un historiador. Foucault siempre me dejaba profundamente insatisfecho" (Casarino, Negri, 152). Negri entiende que Foucault era perfectamente consciente de estas limitaciones. Y de ahí el giro que toman las investigaciones del filósofo francés a mediados de los años setenta, según Negri. Será en la obra de Deleuze, Diferencia y Repetición, sostiene Negri, donde por primera vez se confrontan y resuelven los problemas que dificultaban el proyecto de Foucault.

La misma definición de biopolítica que Negri halló en Foucault no se encuentra, en última instancia, presente en su obra. Antes bien, serán Deleuze y Guattari quienes, a su juicio, ofrecen una comprensión propiamente post-estructuralista de la biopolítica, capaz de renovar el materialismo histórico anclándolo en la cuestión de la producción del ser social. La inspiración inicial y el punto de partida de la investigación de Negri sobre la biopolítica fue, pues, la lectura que Deleuze hizo de Foucault ${ }^{3}$.

3 Para Negri, las principales corrientes de la interpretación de Foucault no comprenden adecuadamente la naturaleza dual de la biopolítica. Roberto Esposito, Comunidad, inmunidad y biopolítica (Barcelona: Herder, 2009) 
Si bien Negri reconoce su deuda con Mil Mesetas, y en relación al poder entiende que siempre resta potencia a la vida, esta vida no la concibe como algo personal o como un flujo -razón por la cual es en gran medida antibergsoniano. Su concepción de la vida no es vitalista. Concibe la vida, más bien, como multitud de singularidades, que se juntan o se separan y, al hacerlo, constituyen, producen juntas el momento de la constitución. Una multitud que se halla continuamente sometida a la sustracción de poder.

Con todo, en el planteamiento de Negri siempre permanecen diferencias importantes y sustanciales que separan sus posiciones de las de los filósofos franceses. En Marx más allá de Marx, Negri señalaba las limitaciones de la corriente post-estructuralista que, en última instancia, radicaban en el hecho de no identificar un poder constituyente. En efecto, si para Deleuze el sujeto es siempre un residuo dejado por el deseo, una forma de dominio, para Negri el sujeto es el lugar de la identidad entre la fuerza productiva del ser y su constitución misma. Deleuze y Negri parten de una misma raíz spinoziana, pero adquieren dos enfoques distintos: para Deleuze, la ontología como experimentación liberadora; para Negri, la ontología como fenomenología de la praxis constitutiva del sujeto colectivo, es decir, 'lo social' debe ser pensado como un sujeto constituyente.

\section{'Lo común' en la obra de Antonio Negri}

El concepto de 'lo común', tal como es presentado en Commonwealth por Hardt y Negri, toma forma dentro de la crisis de la medida del valor en Marx: la producción de la 'fábricasocial' ${ }^{4}$ no se puede medir, y el tiempo ya no es la unidad de medida de tal producción.

A diferencia del régimen de fábrica, en el postfordismo, "las formas centrales de la cooperación productiva ya no las crea el capitalista como parte del proyecto de organización del trabajo sino que, cada vez más, emergen de las energías productivas del trabajo mismo" (Hardt, Negri, 2004, 143). Esta es, de hecho, la característica clave del trabajo inmaterial para Negri: producir comunicación, relaciones sociales y cooperación. El aspecto central del paradigma de la producción inmaterial sobre el que Negri pone luz es el de su estrecha relación con la cooperación, la colaboración y la comunicación: en suma, su fundamento en 'lo común' (Hardt, Negri, 2004, 178). En el postfordismo, 'explotación' es expropiación de 'lo común'. En otras palabras, 'lo común' se ha convertido en el locus de la obtención de plusvalía:

La explotación consiste hoy en la apropiación privada de una parte o de la totalidad del valor producido en 'común'. Las relaciones y la comunicación producidas son ‘comunes' por su propia naturaleza, pero el capital consigue la apropiación privada

analiza el terreno de la biopolítica principalmente desde el punto de vista de la gestión normativa de las poblaciones; y Giorgio Agamben, Ensayos sobre biopolítica (Paidós: Argentina, 2007) acepta que la biopolítica es un terreno ambiguo y de conflicto, pero concibe que la resistencia actúa solo en su límite más extremo, en los márgenes de una forma totalitaria de poder, al borde de la imposibilidad.

4 Para el operaismo, el capital se ha convertido en una 'fábrica-social', ha extendido los procesos de valorización al conjunto de la sociedad. La 'subsunción real' marxiana no solo implica que los trabajadores se han convertido en parte de la máquina -o son, en sí mismos, la máquina-, sino que toda la sociedad es subordinada al movimiento expansivo e ilimitado del capital. 
de parte de su riqueza: lo elaborado en 'común' pasa al dominio privado (Hardt, Negri, 181-182).

El capitalismo postfordista no es tanto una estructura de explotación que se pueda comprender exclusivamente en relación al concepto de plusvalía, sino un dispositivo de captura y apropiación de una producción social. La tesis que formula Negri es que la explotación es precisamente la captura y la expropiación de formas del producto de la cooperación social. El capital es un virus que vive del trabajo ajeno, solo puede sobrevivir parasitando el cuerpo social de la producción; el capital vive del trabajo como un virus del ADN. En este sentido, el capital, más que un 'leviatán', es una relación social: no produciría riqueza si no pudiese extraerla, si no pudiese expropiársela al trabajo vivo:

En todo momento del desarrollo del modo de producción capitalista, el capital ha propuesto siempre la forma de la cooperación. Esta forma tenía que ser funcional a la forma de explotación, cuando no realmente inherente a la misma. Del mismo modo, durante el período de la acumulación primitiva, cuando el capital englobó y constriñó a las formas preexistentes de trabajo a su propia valorización, fue el capital quien impuso la forma de cooperación, consistiendo ésta en el vaciamiento de las conexiones preconstituidas de los sujetos trabajadores tradicionales. En la actualidad, por el contrario, la situación ha cambiado completamente. El capital se ha convertido en una fuerza hipnotizadora, hechizadora, en un fantasma, en un ídolo: a su alrededor giran procesos radicalmente autónomos de autovalorización y únicamente el poder político logra forzarlos, con la zanahoria o con el palo, para que comiencen a amoldarse a la forma capitalista. La transferencia de lo económico a lo político, que se produce en la actualidad, y en dimensiones globales a la vida social productiva, se produce no porque lo económico sea ahora un determinante menos esencial, sino porque únicamente mediante medios políticos puede substraer a la actividad económica de la tendencia que le lleva a mezclarse con lo social y a realizarse en la autovalorización. Lo político se ve forzado a ser la forma-valor de nuestra sociedad (Guattari, Negri, 1999, 102).

Se podría decir que el capital opera como una máquina de captura de un sustrato -la cooperación social-, que mantiene una situación de anterioridad ontológica, porque la cooperación social comienza fuera de la empresa. Es, pues, un proceso previo e inmanente al mismo tiempo: se da en el interior de la relación capitalista, pero el capital no lo produce.

En los modos de producción postfordistas, la fuerza de trabajo se encuentra en el interior de la sociedad del capital. En el curso de su desarrollo, el capital la ha reconducido de modo creciente bajo su dominio. El control capitalista sobre esta nueva fuerza de trabajo se ejerce a posteriori: ya no en la determinación de los presupuestos organizativos que posibilitaban la productividad social, sino a través de la expropiación de una productividad que continuamente desborda los límites de la valorización. El trabajo asalariado es hoy un campo de heterogeneidad que no puede ser definido únicamente por la relación de subordinación a un empleador, sino también por las diversas conexiones con el afuera de la empresa.

Si en el capitalismo industrial el control de las máquinas era una condición para la acumulación, en el capitalismo postfordista la acumulación se funda en la apropiabilidad y en 
el control del saber y el conocimiento social. En otras palabras, el conocimiento social -es decir, el general intellect- constituye hoy el eje del proceso de creación de riqueza. Para Negri, las transformaciones de las modalidades que adopta la explotación descrita no excluye la afirmación marxista central: que solo la fuerza de trabajo produce plusvalor y riqueza.

\section{La lectura negriana de los conceptos de 'biopolítica' y 'biopoder' en la obra de Michel Foucault}

De la obra de Foucault, Negri ha prestado especial atención a los conceptos de 'biopoder' y 'biopolítica'. Sin embargo, toma esta lectura en una dirección diferente, pues el concepto de 'biopolítica', a su juicio, necesita en última instancia encarar y abordar la cuestión del trabajo. La necesidad de abordar los conceptos desde la cuestión del trabajo, una ontología del hacer, está siempre presente en la obra de Negri, es una constante que nace de su definición como marxista, y, como tal, de la idea siempre vigente de que el mundo se construye a partir del trabajo vivo.

En este sentido, entiende su definición de la 'biopolítica' como una ampliación de la investigación que Foucault había emprendido: en lugar de hacer caso omiso o dejar de lado la elaboración que Foucault hizo de la 'biopolítica' en el contexto del ejercicio de la sexualidad, adoptó esa elaboración y la amplió a fin de dar cuenta de la construcción general del cuerpo en los ámbitos indistinguibles de la producción y la reproducción, es decir, en el ámbito del trabajo inmaterial. Esa ampliación de la investigación le permitió también clarificar algo que en Foucault había quedado, a juicio de Negri, relativamente indefinido: la relación entre 'biopolítica' y 'biopoder'.

Si permanecemos demasiado atados a un análisis filológico de los textos de Foucault, nos advierte Negri, podríamos pasar por alto la cuestión central: sus análisis del 'biopoder' apuntan no solo a una descripción empírica de cómo funciona el poder para y a través de los sujetos, sino también al potencial de producción de subjetividades alternativas, indicando de tal suerte una distinción en la afirmación de Foucault según la cual la libertad y la resistencia son precondiciones necesarias para el ejercicio del poder (Hardt, Negri, 2011, 100). Para Negri, Foucault reinserta la ontología de la producción dentro del tejido biopolítico. La arqueología y la genealogía foucaultianas se convierten en parte de una teoría de la producción del ser.

Para Negri, en tanto la vida se ha vuelto enteramente productiva, interpreta la 'biopolítica' no como un flujo paralizante sobre el conjunto de la sociedad, sino como la apertura de nuevas posibilidades de combinar creación y resistencia. Así, identifica el 'biopoder' con la nueva figura de la soberanía y del mando sobre el trabajo -el mando financiero, por ejemplo. El 'biopoder' es el poder sobre la vida, se configura sobre la reproducción del individuo y sobre la potencia 'biopolítica' de los cuerpos. La 'biopolítica', por el contrario, la identifica con las potencias productivas de la vida: la producción de afectos, de lenguajes a través de la cooperación social, la interacción de cuerpos y deseos.

También afirma Negri que la 'biopolítica' es "la creación de nuevas subjetividades que se presentan a la vez como resistencia y como desubjetivación" (Hardt, Negri, 2011, 77). Es el terreno sobre el que la fuerza de trabajo ejercita a la vez su capacidad de producción y de resistencia. El campo de inmanencia es propuesto como el terreno biopolítico creativo. 
Es la expresión del deseo vital de los sujetos que se enfrenta con el 'biopoder'. Decir que la vida resiste significa afirmar su potencia, es decir, su capacidad de creación, de invención, de producción y de subjetivación. Es lo que Negri llama 'biopolítico': la resistencia de la vida al poder, dentro de un mismo poder que ha investido la vida.

En la ontología de Negri, por un lado, hay una potencia que crea, produce, constituye - lo que Deleuze y Guattari llaman 'deseo'-; y, por otro, hay un poder que resta y ciega. Siempre que describe las diversas formas que adopta el poder -la dominación del Estado o el poder de la explotación del capital, etc. - lo hace en términos negativos, privativos, que sustraen. Es decir, parte del dualismo spinozista, que está estructurado por una potencia productiva -nuestro deseo-; y, por otro, por un poder negativo, el momento en el que nuestro deseo deja de expandirse. Nuestro deseo siempre alcanza un límite, que Negri identifica con el Estado, con el capital, etc.

\section{La 'empresarialización de la vida’: el olvido de Antonio Negri}

En nuestra opinión, desde la concepción de 'lo común' de Negri es imposible rastrear los modos en que los individuos interiorizan las necesidades del capital, como elemento fundamental en los procesos de subjetivación postfordistas. Esta deficiencia que hallamos en el análisis de Negri imposibilita, a nuestro juicio, el abordaje del neoliberalismo como modo de gobierno, como dispositivo de control de la subjetividad y de formas de vida. Consideramos, pues, que es del todo pertinente impugnar y complementar el análisis negriano desde la figura propuesta por Foucault del 'empresario de sí'.

Y es que para Negri, en la producción biopolítica el capital no determina la disposición cooperativa, sino que el trabajo mismo produce cooperación autónomamente respecto al poder de mando capitalista. A su juicio, la fuerza de trabajo biopolítica está tornándose cada vez más autónoma, mientras que el capital se limita a gravitar sobre ella de forma parasitaria a través sus aparatos de captura, sus mecanismos de explotación y redes financieras.

'Lo común' siempre es presentado por Negri como una relación positiva y cualitativamente nueva entre el trabajo y el capital, a través de la cual el trabajo siempre se convierte en una labor autónoma, autoorganizada, productora de cooperación social. Para Negri, todas las actividades que tienen lugar en el marco de la producción postfordista se crean de forma interna al trabajo y de forma externa al capital. Una relación que, además, siempre contiene la posibilidad de desarrollar formas cooperativas de trabajo. Desde nuestra perspectiva, el problema de esta concepción negriana radica en considerar que el desarrollo de la cooperación social es siempre un proceso autónomo y autoorganizado. En Commonwealth, Negri redefine la materialidad de las transformaciones postfordista para comprender 'lo común' como algo que no existe, sino que se crea, se produce. De ahí que Negri no hable del 'común' sino de 'lo común'. Su concepción de ‘lo común’ parte de concebir el marxismo como una forma ontológica, una acción ontológica que genera el proceso histórico por medio del conflicto que crea, determina y produce. Negri conceptualiza el mundo como un proceso material y afirmativo de constitución.

Desde la perspectiva negriana, en la medida en que la producción deviene cada vez más inmaterial, lo fundamental es cómo escapar a la captura que realiza el capital de la riqueza producida. En lo fundamental, consideramos que Negri acierta en proponer la explotación 
postfordista como expropiación y captura. Sin embargo, nos parece que no siempre la formación de 'lo común' y la organización del trabajo contienen la anterioridad ontológica al proceso de captura que él describe. Y es que el proceso que Negri siempre presenta como anterior y autónomo, muchas veces es un proceso que contiene una anterioridad ontológica bien distinta, esta es, la interiorización por parte de la fuerza de trabajo de las necesidades del capital ${ }^{5}$. Sucede entonces que el proceso de producción es, en efecto, inmanente -el postfordismo es un plano de inmanencia- en el cual se produce no un desarrollo de la cooperación social, determinada por una lógica propia, que luego es capturada y expropiada por el capital, sino un desarrollo automático de la interiorización de las necesidades del capital y la lógica del mando. Dado que la producción de la cooperación social está estructurada en beneficio de la acumulación, no siempre el trabajo puede tener ese carácter autónomo que señala Negri. Existe un compromiso subjetivo de la fuerza de trabajo con el capital.

Desde esta perspectiva, entendemos que Negri no utilice la figura del 'empresario de sí mismo' de Foucault -a pesar de ser un gran conocedor de su obra- como figura fundamental en el análisis de la naturaleza de la fuerza de trabajo en el postfordismo ${ }^{6}$. Al presentar Negri 'lo común' siempre como una anterioridad ontológica autónoma, no tiene necesidad alguna de rastrear en 'lo común' los procesos de subjetivación que comporta la necesaria adecuación a las necesidades del capital que ha de asumir la fuerza de trabajo.

Así, Negri obvia que el trabajo inmaterial contiene elementos de autoempresa, que el objetivo de la regulación empresarial de la vida es que cada pequeño aspecto de la cotidianidad sea comprensible como relación empresarial, y no como un proceso cooperativo y autónomo. Por una parte, es cierto que el trabajo, en el postfordismo, está inserto en una producción común, cooperativa; pero, por otra, es cierto también que el trabajador es hoy un 'empresario de sí mismo', en la medida en que pone en juego un capital de conocimientos.

Con ello, no queremos negar validez al proyecto negriano -y por extensión autonomista- a la posibilidad de articular una socialización autónoma, al margen de la valorización capitalista, a partir de nuevas institucionalidades fundadas en la fuga y el éxodo. Por el contrario, nuestra crítica se dirige a la determinación ontológica en la que Negri inscribe su

5 Escribe Silvia Federici (2013, 200-201) al respecto: "lo común no puede ser producido cuando tenemos que ofrecerles bebidas a los clientes sin importar sus posibles problemas de hígado o si debemos convencerles de comprar un vestido, un coche o unos muebles que puede que no sean capaces de pagar, sin escatimar en hincharles el ego, dando consejos y comentarios según prescripciones previas".

6 Figura que sí es utilizada en las reflexiones de otros autores (post)operaistas, sobre todo por Maurizio Lazzarato, quien elabora una fuerte crítica a la ontología de raíz hegeliana y apuesta por una ontología pluralista partiendo de la filosofía de la diferencia. Su diálogo con los otros autores (post)operaistas es permanente, con los que además comparte una larga trayectoria intelectual y política, pero discrepa -fundamentalmente con Negri y Virno- del proyecto de reactualización del marxismo. Sus críticas siempre permanecen en el interior de la corriente, señalando los posicionamientos filosóficos que no logran liberarse de la dialéctica amo/esclavo y su sometimiento a la lógica de la totalidad; si bien por momentos Lazzarato fideliza con el proyecto deleuziano sin necesidad de diálogo con el (post)operaismo. Así, el acercamiento de Lazzarato a la obra de Marx no es a partir de la relación capital/trabajo, entendida como origen y fuente del mundo y de las relaciones de poder, sino a partir de todos los dispositivos, siendo el trabajo un dispositivo más entre otro. Para captar la dinámica del capitalismo postfordista no se refiere a las fuerzas "inmensas, exteriores y superiores" de la dialéctica capital/ trabajo, sino a las fuerzas multiplicadas, infinitesimales e internas. A partir de la obra de Deleuze establece la ruptura entre el marxismo y el pluralismo, es decir, entre una ontología de la producción y una ontología de la creación. 
concepción de 'lo común', al hecho de que obvie que cada sujeto posee un capital propio, que el individuo se convierte en un espacio gestionable. Todo el esfuerzo teórico negriano está basado en encontrar -inventar- una forma social en la cual la productividad pueda ser puesta en acto. Pero Negri obvia que esa potencia, anterior al acto, las singularidades de la cooperación social, se manifiestan también como 'yo empresa', como autogestión declinada al modo de 'empresario de sí mismo'. En las teorías del capital humano, el individuo se comporta como un capital. De este modo, conduce a

multiplicar el modelo económico para hacer de él un modelo de relaciones sociales, un modelo de existencia misma, una forma de relación del individuo consigo mismo, con el tiempo, con el entorno, con su futuro, con la familia, con su pareja, sus seguros y su jubilación, se convierta en una suerte de empresa permanente y múltiple (Foucault, 2008, 277).

Desde el punto de vista del trabajador, el salario ya no es solo el precio de venta de su fuerza de trabajo; es un ingreso de su capital, esto es, de un capital humano indisociable de quien lo posee: trabajador y capital son una y la misma cosa. En el texto de Foucault del año 1979, El Nacimiento de la biopolítica, aparece plasmada una nueva concepción de lo social y de la fuerza de trabajo. Muestra en este seminario los procesos que han consolidado la privatización de lo social y el surgimiento del hombre 'empresario de sí mismo': "es el hombre empresario de sí mismo, siendo él su propio capital, siendo para él mismo su propio productor y siendo para él mismo la fuente de sus ingresos" (Foucault, 2008, 265).

Foucault describe la transformación del trabajador en 'capital humano': debe garantizarse a sí mismo la formación, el crecimiento, la acumulación, el mejoramiento y desarrollo de sí como capital. El trabajador ya no es un mero factor de producción. Es, en sentido estricto, una fuerza de trabajo, un capital-habilidad, una máquina de habilidades. Para analizar al trabajador 'empresario de sí mismo', es necesario, pues, pasar al exterior del trabajo: abandonar el análisis de las estructuras del proceso económico, y centrarnos en el análisis del individuo, de su subjetividad y de las condiciones de producción de vida. Trabajo sin fin, y construcción sin fin de sí mismo. De hecho, en el postfordismo, la línea divisoria entre el hecho de trabajar y buscar trabajo se ha disuelto: buscar un trabajo es también estar ya trabajando.

Se trata, pues, de interrogar ese 'afuera', porque la empresarialización de la vida no se deriva de las formas de racionalidad internas a la lógica de la producción, sino de una racionalidad externa a ella y que Foucault llama "el gobierno de los hombres". Esta es la novedad que Foucault introduce en la historia del capitalismo, y que hoy adquiere relevancia: "el problema de la relación entre economía y política se resuelve mediante técnicas y dispositivos que no proceden ni de la política ni de la economía. La economía se transforma en economía de las conductas, en "economía de las almas"” (Lazzarato 2005, 24).

Ir más allá de la racionalidad interna a la lógica de la producción es un límite que encontramos en la obra de Negri, porque su concepción de la producción es autoproductiva y autorrefencial, por lo que carece de todo exterior. Y es que existe una constante que acompaña siempre el pensamiento de Negri: siempre procura referir todo concepto a la cuestión del trabajo. En la obra de Negri, el trabajo no es un aspecto entre otros, sino la actividad social que constituye a la sociedad capitalista como tal. Negri redefine la noción de trabajo 
de Marx y la adecúa, en un sentido ontológico, a las nuevas dimensiones de la producción postfordista. Interpreta el trabajo vivo en términos de una verdadera refundación ontológica. Para Negri, la explotación de la fuerza de trabajo colectiva sigue siendo el eje básico que define el antagonismo social. Desde la perspectiva negriana, es claro que el dualismo que constituyen el trabajo y el capital no es en absoluto un dualismo metafísico, sino un dualismo empírico y materialista que no puede ser superado. Por ello, la explotación es siempre una máquina de producción de subjetividad, un proceso de formación de sujetos a través de la lucha de clases. Negri siempre retorna al análisis y la crítica del trabajo con el objeto de identificar las razones de la explotación, sin abandonar nunca la perspectiva marxiana.

Por el contrario, y haciendo estallar los límites del pensamiento negriano, para Foucault el neoliberalismo constituye un nuevo modo de gubernamentalidad en el que las personas se rigen y gobiernan a sí mismas. Foucault resume en el concepto de 'movilización' el compromiso y la activación de la subjetividad por las técnicas de gestión empresarial y el gobierno social. Desde esta nueva perspectiva, no es que la vida sea puesta a trabajar -el devenir biopolítico que señala Negri-, es que la vida misma deja de ser un dato objetivo para convertirse en algo subjetivo: vivir es trabajar nuestra propia vida, o dicho más claramente, vivir es gestionar nuestra propia vida. No es necesario que uno cree su pequeña empresa individual para ser 'empresario de sí mismo': basta con comportarse como si lo fuera, adoptar su lógica, sus actitudes, su manera de relacionarse con el mundo, consigo mismo y con los otros. El individuo, entendido como empresario de sí mismo, es la culminación del capital como máquina de subjetivación. En cambio, la subjetividad en Negri siempre está atravesada por una dinámica, una construcción: el conatus del trabajo vivo.

\section{La temporalidad propia del 'empresario de sí mismo': de la captura del pasado antago- nista a la objetivación del tiempo futuro}

La metodología autonomista está fundada en la 'revolución copernicana' que inaugura la obra de Mario Tronti Obreros y Capital'. Negri, siguiendo la metodología operaista, da cuenta de cómo diferentes luchas a lo largo de la historia han sido el antecedente a un cambio radical en el modo de producción. Dicho en otros términos, el capital nunca pasa voluntariamente a una fase superior de modo de producción. La innovación capitalista es

7 Esta obra, de 1969, marca la ruptura teórica que inaugura el operaismo. Partiendo de una reelaboración filosófica de la relación entre el marxismo y Hegel, que por aquellos años era lugar común en cualquier posicionamiento teórico, Tronti expresó la llamada 'revolución copernicana' con aquél "primero las luchas, luego el desarrollo capitalista". El primer número de la revista Classe Operaia, cuyos números siempre tenían una orientación monográfica, Lenin in Inghilterra, comenzaba con el famoso artículo homónimo de Tronti, en el que exponía con claridad el giro radical en el análisis teórico de la relación entre luchas obreras y desarrollo capitalista. Para Tronti, la resistencia siempre es anterior en relación al poder; las revueltas de la clase trabajadora anteceden y prefiguran los desarrollos posteriores del capital. En otras palabras, las revueltas constituyen una fuerza creativa que, incluso si no sale inmediatamente victoriosa, determinará los modos de desarrollo futuro del capital. Esta proposición hace hincapié en la potencia y en la creatividad de la lucha, reconoce la primacía constituyente de la clase obrera. Los trabajadores no son, pues, un elemento pasivo de los designios capitalistas, "la víctima reactiva pasiva", sino los sujetos activos de la producción, la fuente de innovación de la cual depende el capital. La clase obrera no es solo el sujeto de la explotación, sino también el sujeto de poder; no es solo el sujeto pasivo construido mediante los dispositivos de la dominación capitalistas, sino el sujeto activo que se constituye a sí mismo. 
siempre producto, compromiso o respuesta de una innovación y construcción derivada del antagonismo de los trabajadores. Los contenidos de los dispositivos de captura no surgen de la nada, existe una configuración previa por el ejercicio del poder constituyente antagonista. Así, "toda innovación es la secularización de la revolución” (Guattari, Negri, 93). Para Negri, por tanto, el poder constituyente -la multitud social- siempre precede al poder constituido -las instituciones.

Negri lee los desarrollos del capital en términos de una relación constante, mutuamente determinante, entre estructuras de gobierno capitalistas y las luchas por la liberación. Una relación que no es dialéctica, pues no hay resolución sintética -aufhebung hegeliano. El movimiento propuesto por Negri siempre es el mismo: las luchas de los trabajadores determinan la reestructuración del capital; y, a su vez, esta reestructuración condiciona los términos de las luchas futuras. En otras palabras, en cada ciclo de acumulación capitalista, con cada transformación de la "composición técnica'8 del trabajo, los trabajadores usan los medios a su disposición para inventar nuevas formas de rebelión y autonomía respecto del capital; y, en respuesta a esto, el capital es forzado a reestructurar las bases de la producción, explotación y control, lo cual determina, a su vez, una nueva transformación de la 'composición técnica'. Y, nuevamente, los trabajadores habrán de descubrir nuevas armas con las que subvertir el nuevo orden.

Como vemos, la narrativa que Negri construye para comprender el campo social desde una perspectiva antagonista, es la de un presente fundado en un pasado de luchas recientes, en el antagonismo. El capital es una máquina de captura de luchas y formas de vidas que son previas. Y es que para que el dispositivo pueda capturar, necesita de algo que sea generativo, productivo, ontológicamente anterior a él. Y ese 'origen', para Negri, solo puede ser constituyente. La resistencia es siempre anterior y supone una afirmación libre. La desobediencia, que inaugura el poder constituyente, solo afirma la dimensión anticipatoria de la resistencia en su dimensión productiva constituyente. Al señalar que las luchas preceden y determinan al desarrollo capitalista, lo que propone es un dispositivo material al que corresponde una serie de actos constitutivos.

En lo que sigue, a modo de conclusión, queremos argumentar que la figura del 'empresario de sí mismo' rompe la lógica temporal de la captura capitalista tal como la presenta Negri. No se trataría ya de la captura de un tiempo pasado, sino de la objetivación, en el presente, del tiempo futuro con el objetivo de disponer de él de antemano.

A partir de las ideas que hemos desarrollado de Foucault, podemos decir que en los modos de producción postfordistas, 'ser' consiste en proyectarse, en invertirse. Bajo el sustrato de la teoría del capital humano, cada individuo se ve compelido a asumir su cuerpo como un empresario que gestiona los recursos de los que dispone para producir. La 'empresarialización de la vida' es un proceso de subjetivación acorde al mercado, configura un individuo gobernable en el sentido de la economía del laissez-faire. Dirá Lazzarato: "la

8 El autonomismo italiano, en la década de los ' 60 y '70, realizó una distinción que es decisiva para exponer los objetivos de esta investigación. Trazó la distinción entre la 'composición técnica' de clase y la 'composición política'. Por 'composición técnica' se entiende la relación que la clase obrera tiene con las máquinas, su condicionamiento, las formas tecnológicas de la producción y de la organización del trabajo; y, por 'composición política', las relaciones fundamentales para determinar las formas de organización del proletariado, la historia de sus luchas políticas, de sus organizaciones y la mutación de sus necesidades y deseos. 
economía debe transformarse en economía de las conductas, economía de las almas (¡la primera definición del gobierno de los padres de la Iglesia vuelve a ser actual!)" (Lazzarato, 2005, 21).

Decíamos antes que Foucault resume en el concepto de 'movilización' el compromiso y la activación de la subjetividad por las técnicas de gestión empresarial y el gobierno social. En relación al concepto de 'movilización', Santiago López Petit sostiene que la propia vida deja de estar ligada a un lugar para convertirse en una vida en viaje. La vida se hace radicalmente nómada: al teléfono, navegando por internet, en coche, en avión. Tenemos una vida desterritorializada del espacio y del tiempo (López Petit, 2009). Pero lo paradójico es que el viaje insertado en la vida no lleva a ningún lado, no importa el hacia dónde, solo cuenta el movimiento: "la cultura moderna del riesgo se caracteriza porque no moverse es sinónimo de fracaso, y la estabilidad parece casi una muerte en vida. Por lo tanto, el destino importa menos que el acto de partir" (Sennett, 2000, 91). La vida en viaje es la expresión de un puro 'movilismo' que atraviesa nuestras vidas hasta rehacerlas para adecuarlas al propio movimiento: "más que un cuerpo vibrátil, nos convertimos en un cuerpo oscilante "moviéndose siempre para no llegar" (Guattari, Rolnik, 2006, 103).

En los modos de producción postfordistas, se lleva a cabo una 'movilización total' de la fuerza de trabajo, con el objeto de que active sus capacidades intelectuales y los residuos de creatividad. Se trata de subsumir al capital la dimensión existencial de la misma fuerza de trabajo; de identificar la subjetividad del trabajo con la subjetividad del capital. En relación con la 'movilización total', tiene lugar una empleabilidad absoluta de la fuerza de trabajo, esto es, la posibilidad permanente de ser movilizados - puestos a trabajar. Los seres humanos somos una posibilidad general, hemos devenido una capacidad productiva general.

En relación a esta dimensión temporal del 'empresario de sí mismo' que señala Foucault -'ser' como invertirse y proyectarse hacia el futuro; la 'movilización' como modo de vida en el presente- el 'empresario de sî' es una figura subjetiva fundamental de una técnica securitaria de gobierno tendente a reducir la incertidumbre de las conductas de los gobernados. Al disciplinar a éstos para 'prometer' que serán recompensados en el futuro al comportarse como empresa, el capitalismo dispone de antemano del futuro, porque las obligaciones propias del 'empresario de sî' le permiten prever, calcular, medir, establecer equivalencias entre las conductas actuales y las venideras.

A través de la 'figura del empresario de sí mismo' se articula un dispositivo singular de sujeción de los modos de producción postfordistas, pero inscrita, a su vez, en una lógica invariable, según la cual el capitalismo determina el desplazamiento del presente hacia el futuro como su única razón de ser:

Una lógica de inversión y maximización de beneficios que es también una lógica de hipotecas ontológicas. En este marco, el presente se ve descapitalizado a favor de un futuro que lo es todo. Estrictamente, el presente se des-capitaliza quedando como una inversión necesaria y prescindible, al servicio de un producto ulterior que es la única realidad relevante. El presente, diríamos, se consume (Martínez Rodríguez, 2001, 5).

Así, 'la empresarialización de la vida' se acomoda a la lógica de la plusvalía y se ve reducida al cálculo de un beneficio. La explotación del futuro distingue al 'empresario de 
sí mismo' de cualquier forma de intercambio mercantil de la fuerza de trabajo que hayamos conocido hasta ahora. La economía neoliberal es una economía del tiempo: el neoliberalismo es una economía vuelta hacia el porvenir. Devenir 'empresario de sí mismo' no tiene más que una finalidad: objetivar el futuro para poder disponer de él de antemano.

En conclusión, Negri está convencido de que en el interior del sistema siempre hay recursos para generar algo nuevo desde una concepción revolucionaria de la política, desde la perspectiva de las políticas emancipatorias. La fuerza del capitalismo es también la creatividad de la multitud. Desde esta perspectiva, el antagonismo siempre presenta dos caras de la misma moneda de un mismo fenómeno: la cara opresiva, en un lado; y la cara emancipatoria, en el otro. Si bien no se trata de una unidad dialéctica en un sentido hegeliano, encuentra algo estructural en el movimiento de la emancipación que hace que no haya necesidad de acontecimiento.

En el materialismo histórico en el que Negri inscribe su filosofía sobrevienen instancias dialécticas cargadas a menudo de tensiones deterministas, no hay horizonte intempestivo. No existe la posibilidad de las creaciones absolutas, intempestivas, imprevisibles, porque ya están dadas o implicadas en la estructura. La ontología de Negri encierra la posibilidad de la novedad, del acontecimiento y los sujetos en una relación preconstituida: la relación dialéctica entre capital y trabajo ostentaba el monopolio de la invención y de los procesos de subjetivación.

Es por ello que se hace difícil pensar la inclusión de la figura del "empresario de sí mismo" en el seno de la ontología negriana sin que ésta sea puesta en jaque. La determinación ontológica en la que Negri inscribe su concepción de ‘lo común' choca con una figura que es, ante todo, una vuelta al porvenir, una explotación de un tiempo futuro que desconoce cualquier determinación previa en la que encontrar una explicación causal. Es esta dimensión temporal propia del "empresario de sí mismo", la explotación de un tiempo futuro que no encuentra su origen en un pasado antagonista, la que hace a Negri poner entre paréntesis las reflexiones foucaultianas al respecto.

\section{Bibliografía}

Berardi, F. (Bifo) (2013), Félix. Narración del encuentro con el pensamiento de Guattari, cartografía visionaria del tiempo que viene, Buenos Aires, Cactus.

Casarino, C., Negri, A. (2011), Elogio de lo común, Barcelona, Paidós.

Cocco, G., Negri, A. (2003), Diálogo sobre la globalización, la multitud y la experiencia argentina, Buenos Aires, Paidós.

Deleuze, G. (1994), Mil mesetas: capitalismo y esquizofrenia, Valencia, Pre-Textos.

Federicci, S. (2013), Revolución en punto cero. Trabajo doméstico, reproducción y luchas feministas, Madrid, Traficantes de Sueños.

Foucault, M. (2008) El Nacimiento de la biopolítica. Curso en el Collège de France (19781979).

Guattari, F., Negri, A. (1999), Las verdades nómadas \& General Intellect, poder constituyente y comunismo, Madrid, Akal.

Guattari, F., Rolnik, S. (2006), Micropolíticas. Cartografías del deseo, Buenos Aires, Tinta Limón. 
Hardt, M., Negri, A. (2000), Imperio, Barcelona, Debate.

Hardt, M., Negri, A. (2004), Multitud. Guerra y democracia en la era del Imperio, Barcelona, Debate.

Hardt, M., Negri, A. (2011), Commonwealth. El proyecto de una revolución del común, Madrid, Akal.

Lazzarato, M. (2005) "Biopolitique/Bioéconomie”, Multitudes, núm. 22.

López Petit, S. (2009), La movilización global. Breve tratado para atacar la realidad, Madrid, Traficantes de Sueños.

Martínez Rodríguez, A. (2011), "Capitalizar la experiencia: mesianismo, capital y modernidad”, en Bermejo Salar, A. (ed.) Umbrales filosóficos: posicionamientos y perspectivas del pensamiento contemporáneo, Murcia, Editum.

Negri, A. (1982), Macchina tempo: rompicapi, liberazione, costituzione, Milàn, Feltrinelli.

Negri, A. (1993), "Entrevista de Guilles Deleuze con Toni Negri”, Magazín Dominicial, núm. 511.

Negri, A. (2003), Del retorno. Abecedario biopolítico, Barcelona, Debate).

Negri, A. (2006), Fábricas del sujeto/ontología de la subversión, Madrid, Akal.

Sennett, R. (2000), La corrosión del carácter: las consecuencias personales del trabajo en el nuevo capitalismo, Barcelona, Anagrama.

Tronti, M. (2001), Obreros y capital, Madrid, Akal. 
